\title{
Development and validation of a simple, fast, isocratic stability indicating RP-HPLC-UV method for the determination of chlorhexidine and its impurity para-chloroaniline in bulk and finished product
}

\author{
TarigG. Mohammed ${ }^{\mathrm{a}, *}$.M.EM. Abdel Aziz ${ }^{\mathrm{a}}$ \\ Chemistry Department, College of Science, Sudan University for Science and Technology, Khartoum, Sudan.
}

\begin{abstract}
A simple, isocraticRP HPLC-UV method was developed for the simultaneous determination of chlorhexidine (CHD) and p-Chloroaniline (pCA) inchlorhexidine mouth rinses. An excellent separation obtainedbyC18 column $(200 \mathrm{~mm} \times 4.6 \mathrm{~mm}, 3 \mu \mathrm{m})$. Mobile phasewas acetate buffer:methanol in a 45:55 ratio,flowrate was $1.0 \mathrm{ml} / \mathrm{min}$. Both ingredient and an impuritywere detected at $254 \mathrm{~nm}$,injection volume was $20 \mu 1$ and the analysis temperature was room temperature.Resolution4.7,retention times was $3.1 \mathrm{~min}$ and $5.7 \mathrm{~min}$ for pCAand CHD respectively. The proposed method was testedforsystem suitability, linearity, range, precision, accuracy, specificity, robustness, detection and quantification limits. The linearity range was $40-160 \mu \mathrm{g} / \mathrm{ml}$ forCHD and0.3-1.2 $\mu \mathrm{g} / \mathrm{ml}$ forpCA.The correlation coefficient of the regression line was 1.000 for both components. Method robustness was tested under nine different conditions using sampleswith a known content. For CHD, the mean of the nine assays was $99.95 \%$ andthe RSD was $0.16 \%$. ForpCA, the mean of the nine assays was $99.98 \%$ and the RSD was $0.24 \%$. The results show that this is a simple method that can be applied to the analysis of Chlorhexidineproductswith satisfactory degrees of accuracy and precision. Due to the selected optimized conditions, this method can be used with the minimum requirements of an isocratic HPLC system.
\end{abstract}

Key words: HPLC-UV; Isocratic; Method validation;Chlorhexidine; p-Chloroaniline

\section{INTRODUCTION}

Chlorhexidine [CHD; 1,1'-hexamethylenebis [5-(4-chlorophenyl) biguanide]] has a wide spectrum of bactericidal and antiviral activity and is a common ingredient in various formulations ranging from skin disinfectants in healthcare products to antiplaque agents in dentistry [1-5]. The presence of two symmetrically positioned basic chlorophenylguanide groups attached to a lipophilic hexamethylene chain (Figure 1) aid in rapid absorption through the outer bacterial cell wall, causing irreversible bacterial membrane injury, cytoplasmic leakage, and enzyme inhibition. [6].This molecule exists as various forms of salts: diacetate, dihydrochloride, or digluconate, mainly differing by their solubilizing abilities in aqueous or oily media. CHD digluconate (or gluconate), as most soluble in water or alcohol, is the most used form in topical dermatology or cosmetic preparations. Aqueous solutions of CHD are most stable within the $\mathrm{pH}$ range of 5-8. Above $\mathrm{pH} 8.0$ CHD base is precipitated and in more acid conditions there is gradual deterioration of activity because the compound is less stable. [7,8]. Chlorhexidine is a chemical antiseptic. It is effective on both gram-positive and gram-negative bacteria. It has both bactericidal and bacteriostatic mechanisms of action; the mechanism of action being membrane disruption, not ATPase inactivation as previously thought.It is also useful against fungi and enveloped viruses, though this has not been extensively investigated. Chlorhexidine is harmful in high concentrations, but is used safely in low concentrations in many products, such as mouthwash and contact lens solutions. By ionization it produces positive ions[9].Hydrolysis yields p-chloroaniline (pCA); the amount is insignificant at room temperature, but is increased by heating above $100^{\circ} \mathrm{C}$, especially at alkaline pH.This cationic molecule (positively charged species) is thus generally compatible with other cationic materials, although compatibility will depend on the nature and relative concentration of the second cationic species. It is, however, possible for a reaction to occur between CHD and the counter-ion (anion) of a cationic molecule which is negatively charged, resulting in the formation of a less soluble CHD salt, which then may precipitate. CHD is incompatible with inorganic anions in all but extremely dilute solutions. CHD is also incompatible with organic anions, such as soaps, sodium lauryl sulphate, sodium carboxymethyl cellulose, alginates, and many pharmaceutical dyes. In certain instances, there will be no visible signs of incompatibility, but the antimicrobial activity may be significantly reduced because of the CHD being incorporated into micelles (ionic clusters). pCA is very toxic if inhaled, swallowed or absorbed through the skin.It may act as a human carcinogen. It is readily absorbed through the skin and it may act as a sensitizer [10]. However, as pCA is the principal product of degradation of CHD and toxic with actual recommend maximum limit of genotoxic impurity[11], it is important to quantify pCA in CHD solution.CHD and pCAwasdetermined using several methodologies such as high 
performance liquid chromatography[12-27], gas chromatography-mass (GC-MS)[28-34],fluorometry [35], UV spectroscopy [36] and time-of-flight secondary ion mass spectrometry [37].In the present work the objective is to design and validate a simple fast and isocratic stability indicating RP-HPLC-UV procedure for the assay of chlorhexidine in presences of its degradation product.<smiles>N=C(NCCCCCCNC(=N)NC(=N)Nc1ccc(Cl)cc1)NC(=N)Nc1ccc(Cl)cc1</smiles>

Figure 1Figure 2

Chlorhexidine Gluconatep-Chloroaniline

\section{Experimental}

\subsection{Chemicals}

Working standards of CHD and pCA, finished productsand excipientswere supplied from Yamani

Medical Products. Methanol and Acetic acid were HPLCgrade(Scharlau Spain). HPLC gradewater was used.

\subsection{Instrumentation}

TheHPLC-UV system consisted of analytical apparatus(Analytical Technologies Limited Corporation, Mumbai,India) with a P2230 pumpSr No P2304051, UV2230 UV-Vis detectorSr No U2304633. This system was connected to a computer loaded with A2000-Solutions software. A C18column (200mmx4.6mm, I.D. 3 $\mu \mathrm{m})$ was used.

\subsection{Methods}

\subsubsection{Standard stock solution}

To prepare stock solutions, $0.1000 \mathrm{~g}$ of CHDand $0.0075 \mathrm{~g}$ of pCAwere weighed accurately and transferred quantitatively to the same 100-ml volumetric flask. The flask was half-filled with the mobile phase and sonicated for 10 minutes, cooled to room temperature, then the volume was completed to the mark with the same solvent.

\subsubsection{Standard solution}

Subsequent dilutions were made from the stock solution with the mobile phase to make solutions with $100 \mu \mathrm{g} / \mathrm{ml}$ ofCHD and $0.3 \mu \mathrm{g} / \mathrm{ml}$ of $\mathrm{pCA}$. The resulting solution was filtered through a $0.45 \mu \mathrm{m}$ membrane nylon filter.

\subsubsection{Assay preparation}

$2 \mathrm{ml}$ of the mouthwash was diluted to $25 \mathrm{ml}$ with the mobile phase to produce a solution containing $0.01 \% \mathrm{w} / \mathrm{v}$ of chlorhexidine gluconatesonicated for 10 minutes, theresulting solution was filtered through a $0.45 \mu \mathrm{m}$ membrane nylon filter.The recovered concentration wascalculated by comparing the analyte response of the samplewith that ofthe standard.

\subsection{Optimized chromatographic conditions}

The mobile phase was composed of acetate buffer and methanol (45:55), usingisocratic elution with a flow rate of $1.0 \mathrm{ml} / \mathrm{min}$. The injection volume was $20 \mu 1$, using a C18 (200mmx4.6mm, $3 \mu \mathrm{m})$. The eluents were monitored at $245 \mathrm{~nm}$.

\section{RESULTS AND DISCUSSION}

\subsection{Validation of the developed and optimized method}

The validation of the developed method was done according to ICH guidelines:system suitability, linearity, specificity, accuracy,interday precision, intraday precision and robustness. 


\subsubsection{System suitability}

The system suitability test is an integral part of the analytical method. For this, amixed standard solution (target concentration) was injectedsix times. Parameters such as RSD\% for the peak area, retention time, resolution and theoretical plates of the peaks were calculated. The resultsfor CHD and pCAare shown in Table 1 and Table 2, respectively.

Table .1System suitability parameters for CHD

\begin{tabular}{||c|c|c|c|c|c||}
\hline \multicolumn{2}{c}{ Area } & \multicolumn{1}{c}{ Retention time } & \multicolumn{1}{c|}{ Resolution } & \multicolumn{1}{c|}{ Theoretical plate } & Asymmetry factor \\
\hline STD 1 & 5659567 & 5.18 & 4.71 & 13420 & 1.13 \\
\hline STD 2 & 5651240 & 5.18 & 4.71 & 13619 & 1.14 \\
\hline STD 3 & 5656282 & 5.17 & 4.69 & 13580 & 1.13 \\
\hline STD 4 & 5650005 & 5.17 & 4.69 & 13576 & 1.13 \\
\hline STD 5 & 5660625 & 5.17 & 4.68 & 13576 & 1.12 \\
\hline STD 6 & 5648577 & 5.16 & 4.65 & 13516 & 1.14 \\
\hline Average & 5654383 & 5.171666667 & 4.68833333 & 13547.83333 & 1.131666667 \\
\hline STDEV & 5141.937 & 0.007527727 & 0.02228602 & 70.76840161 & 0.007527727 \\
\hline RSD & $\mathbf{0 . 0 9 0 9 3 7}$ & $\mathbf{0 . 1 4 5 5 5 7 0 7 1}$ & $\mathbf{0 . 4 7 5 3 5 0 5 8}$ & $\mathbf{0 . 5 2 2 3 5 9 5 5 3}$ & $\mathbf{0 . 6 6 5 1 8 9 3 8 4}$ \\
\hline
\end{tabular}

Table. 2System suitability parameters for $\mathrm{pCA}$

\begin{tabular}{||c|c|c|c|c|c||}
\hline \multicolumn{2}{c}{ Area } & \multicolumn{1}{c}{ Retention time } & \multicolumn{1}{c}{ Resolution } & Theoretical plate & Asymmetry factor \\
\hline STD 1 & 46534 & 3.77 & 4.71 & 15760 & 1.18 \\
\hline STD 2 & 46519 & 3.78 & 4.71 & 15801 & 1.09 \\
\hline STD 3 & 46500 & 3.78 & 4.69 & 15994 & 1.1 \\
\hline STD 4 & 45611 & 3.78 & 4.69 & 16001 & 1.14 \\
\hline STD 5 & 46566 & 3.78 & 4.68 & 16008 & 1.12 \\
\hline STD 6 & 45688 & 3.78 & 4.65 & 15994 & 1.11 \\
\hline Average & 46236.33 & 3.778333333 & 4.68833333 & 15926.33333 & 1.123333333 \\
\hline STDEV & 455.723 & 0.004082483 & 0.02228602 & 113.8220834 & 0.032659863 \\
\hline RSD & $\mathbf{0 . 9 8 5 6 3 8}$ & $\mathbf{0 . 1 0 8 0 4 9 8 3 4}$ & $\mathbf{0 . 4 7 5 3 5 0 5 8}$ & $\mathbf{0 . 7 1 4 6 7 8 5 2}$ & $\mathbf{2 . 9 0 7 4 0 6 2 2 3}$ \\
\hline
\end{tabular}

\subsubsection{Selectivity}

Note: acceptance criteria for impurity $( \pm 15 \%)$.

The mixed standard solution was injected and its chromatogram was recorded (Fig. 3). The sample and placebo solutions were prepared by taking the weight of placebo equivalent to its weight in the test preparation. Based on the chromatograms of the sample (Fig. 4) and placebo (Fig. 5), the placebo solutions showed no peaks at the retention time of the CHD and pCA peaks. This indicates that the excipients used in the formulation did not interfere in the estimation of the active ingredients in the product. The system suitability parameters in the sample chromatogram(Fig. 4) was almost equalto that of the standard chromatogram(Fig. 3) indicating that theexcipientsin the sample did not affect separation.

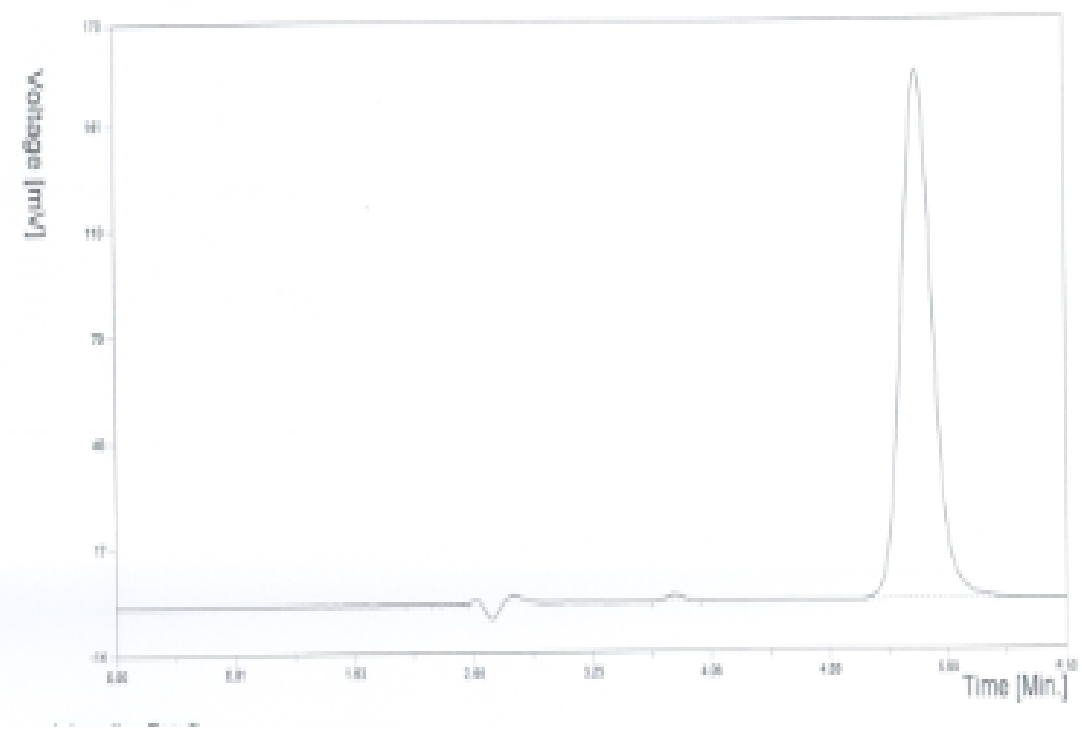

Fig. 3: Chromatogram of the mixed standard solution under the optimized conditions 


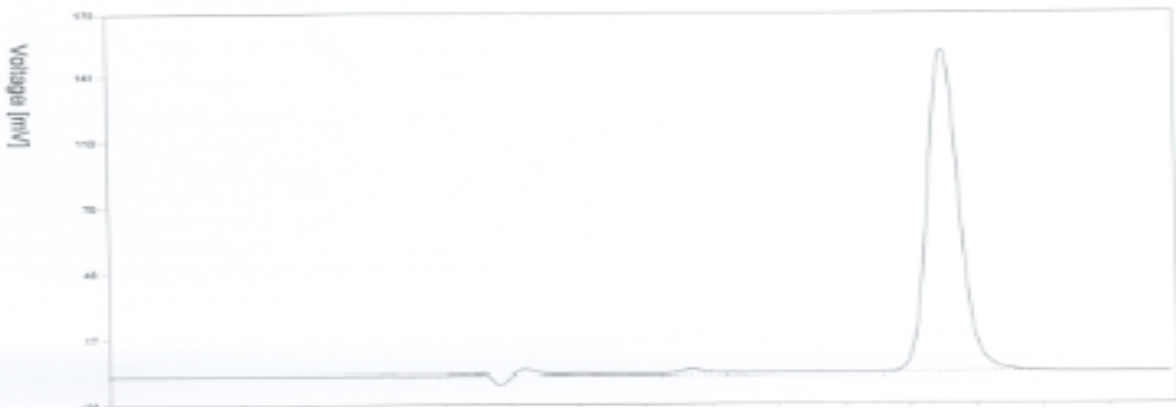

Fig. 4: Chromatogram of a sample solution under the optimized conditions

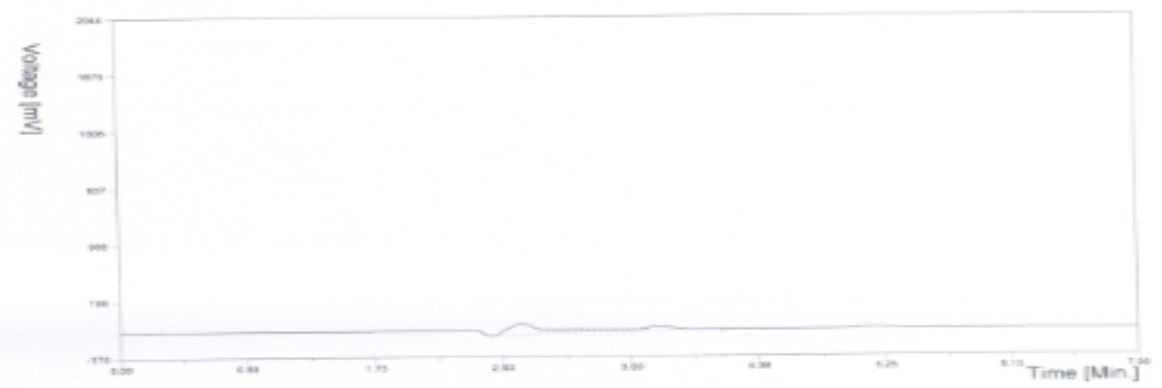

Fig. 5: Chromatogram of a placebo solution under the optimized conditions

\subsubsection{Linearity}

Seven concentrations of mixed standard of CHD and pCA ranging from $40 \%$ to $160 \%$ of the target analyte concentrationswere prepared in mobile phase solution;20, 40.60, 80, 100,120, 140 and 160 $\mu \mathrm{g} / \mathrm{ml}$, and 0.3,0.45, $0.6,0.75,0.9,1.05$ and $1.2 \mu \mathrm{g} / \mathrm{ml}$, respectivly. Eachstandard mixture was injected in triplicate and the mean value of the peak area was used for the calibration curve. The calibration graphwas obtained using XL-STAT 2016. Thelinear regression plotsforCHD (Fig. 6) and pCA(Fig. 7) show that the regression equationswereArea=$\mathbf{1 2 0 4 4 . 1 6 6 6 6 6 6 6 8 8}+56570.3083333333 * \mu \mathrm{g} / \mathrm{mland} A \mathbf{r e a}=\mathbf{8 1 . 8 2 1 4 2 8 5 7 1 4 4 9 4 + 6 1 7 3 6 . 4 2 8 5 7 1 4 2 8 5} * \boldsymbol{\mu g} / \mathbf{m l}$, respectively. The regression coefficient values $\left(\mathrm{R}^{2}\right)$ were found to be 1.000 for both analytes, indicating an excellent degree of linearity.

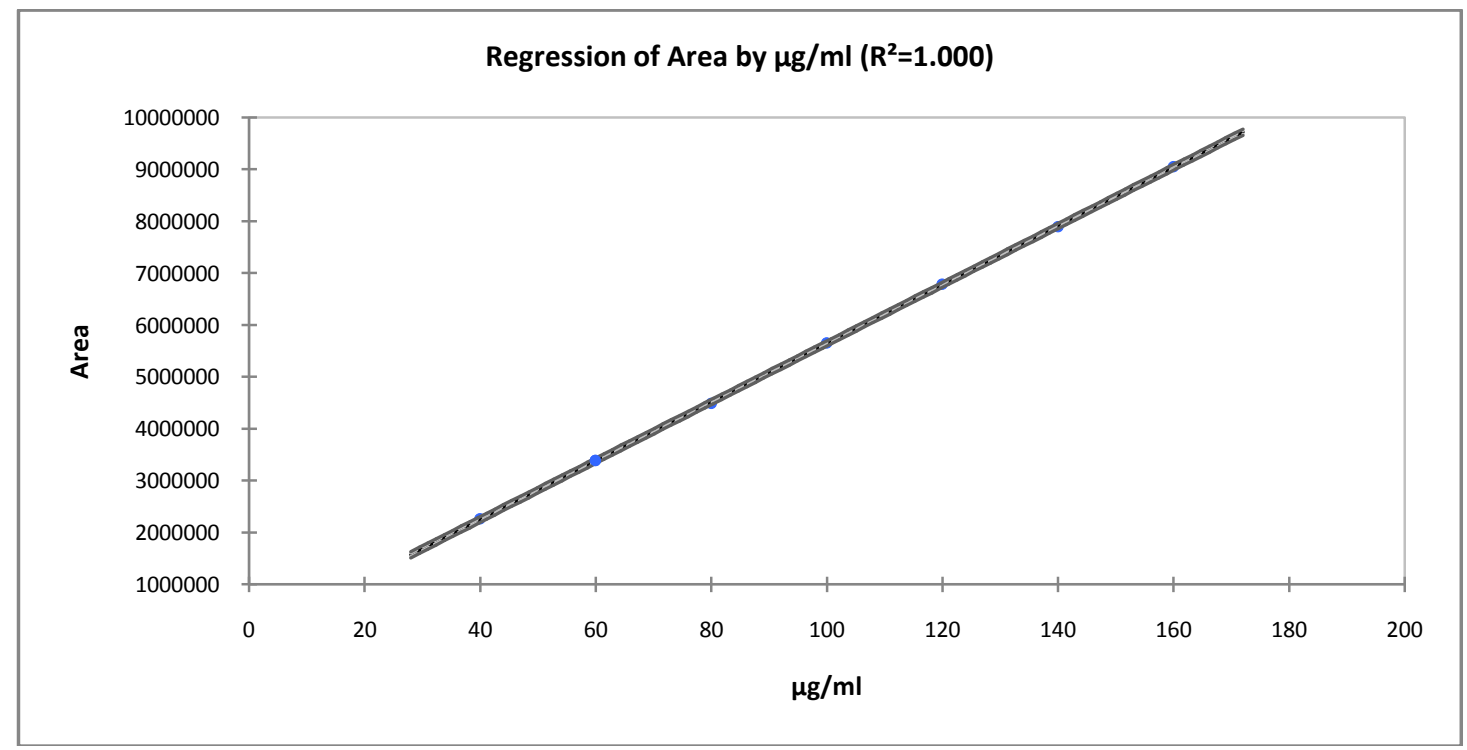

Fig. 6: XL- STAT 2016 plot of $(\mu \mathrm{g} / \mathrm{ml})$ Vs (peak area) - CHD 


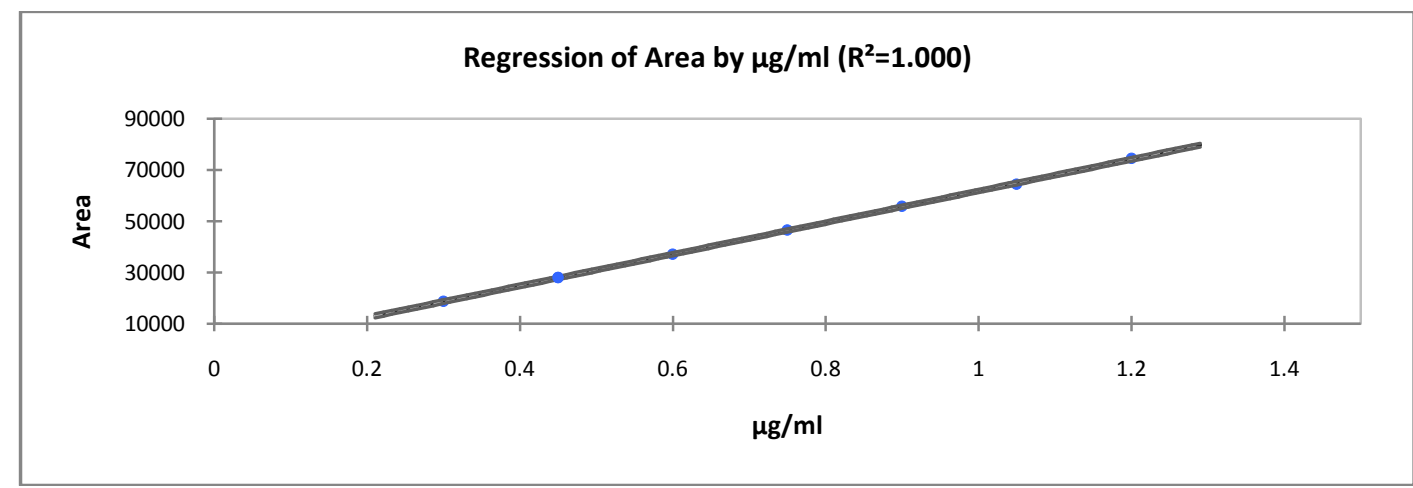

Fig. 7: XL- STAT 2016 plot of $(\mu \mathrm{g} / \mathrm{ml})$ Vs (peak area) - pCA

\subsubsection{Limit of detection (LOD) and limit of quantitation (LOQ)}

The limit of detection (LOD) and limit of quantitation (LOQ) were calculated from linearity data according to ICH [22]:LOD = 3.3* (SD/S) and LOQ $=10 *(\mathrm{SD} / \mathrm{S})$. TheLOD was found to be $0.97626 \mu \mathrm{g} / \mathrm{mland}$ $0.01151 \mu \mathrm{g} / \mathrm{ml}$ for CHD and pCA, respectively, while the LOQ valueswere $3.2541 \mu \mathrm{g} / \mathrm{mland} 0.038389 \mu \mathrm{g} / \mathrm{ml}$, respectively.

\subsubsection{Accuracy}

Seven 100- ml volumetric flasks were labeled, and the placebo equivalent to a tablet's weight was transferred to a different flask. The volume of the mixed standard stock solution required to produce $40 \%, 60 \%$, $80 \%, 100 \%, 120 \%, 140 \%$ and $160 \%$ of thetarget concentration of both CHD and pCA was added to the flasks. The flaskswere half-filled with the mobile phase, sonicated for 10 minutes, cooled to room temperature, then completed to the mark with the same solvent. Subsequent dilutions were made with the mobile phase in the same manner as the standard preparation. The assay was performed on the seven solutions. The recovery percentagefor CHD and pCAwasfound to bewithin the acceptance criteria, i.e. the mean, standard deviations and relative standard deviationsof the recovery percentage of the seven different concentrations (Table 3).

Table 3- Accuracy of the method for CHD and pCA

\begin{tabular}{|c|c|c|c|c|}
\hline \multirow{2}{*}{ Amount added\% } & \multicolumn{2}{|c|}{ CHD } & \multicolumn{2}{c|}{ pCA } \\
\cline { 2 - 5 } & Recovery & Recovery\% & Recovery & Recovery\% \\
\hline $\mathbf{4 0}$ & 40.00906 & 100.0227 & 40.23675 & 100.5919 \\
\hline $\mathbf{6 0}$ & 59.91577 & 99.85962 & 60.41281 & 100.688 \\
\hline $\mathbf{8 0}$ & 79.28594 & 99.10742 & 80.10367 & 100.1296 \\
\hline $\mathbf{1 0 0}$ & 99.96527 & 99.96527 & 100.4801 & 100.4801 \\
\hline $\mathbf{1 2 0}$ & 120.042 & 100.035 & 120.5589 & 100.4657 \\
\hline $\mathbf{1 4 0}$ & 139.5668 & 99.69056 & 139.4567 & 99.61193 \\
\hline $\mathbf{1 6 0}$ & 160.0863 & 100.0539 & 160.9888 & 100.618 \\
\hline Av & & 99.81921 & & 100.36932 \\
\hline STDEV & & 0.3389236 & & 0.3798261 \\
\hline RSD & & $\mathbf{0 . 3 3 9 5 3 7 4}$ & & $\mathbf{0 . 3 7 8 4 2 8 5}$ \\
\hline
\end{tabular}

\subsubsection{Precision}

\subsubsection{Interday precision}

Three 25- $\mathrm{ml}$ volumetric flasks were labeled, and the placebo equivalent to target concentration was transferredto each flask. The volume of the standard stock solution required to produce $80 \%, 100 \%$ and $120 \%$ of the product content of both CHD and pCA was added. The flaskswere half-filled with the mobile phase, sonicated for 10 minutes, cooled to room temperature and completed to the mark with the same solvent. The assay of CHD and pCA in these solutionswas performedfive times in one day; each solution was injected three timesfor each assay. The means, standard deviations and relative standard deviations of the assays were calculated;the method'sinterday precision was foundto be within the permissible limits. The results are shown in Table4.

Table 4-Interday precision of the method for CHD and pCA

\begin{tabular}{||c|c|c|c|c|c|c||}
\hline \multirow{2}{*}{} & \multicolumn{2}{|c|}{$\mathbf{8 0} \%$} & \multicolumn{2}{c|}{$\mathbf{1 0 0} \%$} & \multicolumn{2}{c||}{$\mathbf{1 2 0} \%$} \\
\cline { 2 - 7 } & CHD & pCA & CHD & pCA & CHD & pCA \\
\hline 1st trial & 99.10742 & 100.1296 & 99.96527 & 100.4801 & 100.035 & 100.4657 \\
\hline 2nd trial & 98.99985 & 100.1629 & 100.0016 & 99.99784 & 100.0008 & 100.5486 \\
\hline
\end{tabular}




\begin{tabular}{||c|c|c|c|c|c|c||}
\hline \hline 3rd trial & 99.21989 & 100.1846 & 99.78585 & 100.0137 & 99.61658 & 100.4723 \\
\hline 4th trial & 99.07551 & 100.19 & 99.96394 & 100.0807 & 100.006 & 100.4843 \\
\hline 5th trial & 99.09971 & 100.2476 & 99.98999 & 100.013 & 99.79884 & 100.0199 \\
\hline Avg. & 99.10048 & 100.1829 & 99.94132 & 100.1171 & 99.89142 & 100.3982 \\
\hline STDEV & 0.07915 & 0.043258 & 0.088395 & 0.205474 & 0.180131 & 0.213999 \\
\hline RSD & $\mathbf{0 . 0 7 9 8 6 9}$ & $\mathbf{0 . 0 4 3 1 7 9}$ & $\mathbf{0 . 0 8 8 4 4 7}$ & $\mathbf{0 . 2 0 5 2 3 4}$ & $\mathbf{0 . 1 8 0 3 2 7}$ & $\mathbf{0 . 2 1 3 1 5}$ \\
\hline
\end{tabular}

\subsubsection{Intradayprecision}

Three $25 \mathrm{ml}$ volumetric flasks were labeled, and aplacebo equivalent to target concentration was transferred to each flask. The volume of the standard stock solution required to produce $80 \%, 100 \%$ and $120 \%$ of the product content of both CHD and pCA was added. The flasks were half-filled with the mobile phase, sonicated for 10 minutes, cooled to room temperature and completed to the mark with the same solvent. Theassay was performed on these solutions three times on three different days. The solutions were injected three times for each assay. The means, standard deviations and relative standard deviations of the assays were calculated; the method's intraday precision was foundto be with the permissible limits. The results are shown in Table 5 .

Table 5- intraday precisionof the method for CHD and pCA

\begin{tabular}{|c|c|c|c|c|c|c|}
\hline & \multicolumn{2}{|c|}{$\mathbf{8 0 \%}$} & \multicolumn{2}{c|}{$\mathbf{1 0 0 \%}$} & \multicolumn{2}{c|}{$\mathbf{1 2 0 \%}$} \\
\cline { 2 - 7 } & CHD & pCA & CHD & pCA & CHD & pCA \\
\hline Day 1 & 99.102559 & 100.1375 & 99.960367 & 100.4881 & 100.03007 & 100.4737 \\
\hline Day 2 & 98.753796 & 100.6066 & 99.765273 & 99.85019 & 99.21924 & 100.1698 \\
\hline Day 3 & 100.28873 & 100.249 & 99.475039 & 100.4019 & 100.56168 & 99.90645 \\
\hline Avg. & 99.381696 & 100.331 & 99.73356 & 100.2467 & 99.890462 & 100.1833 \\
\hline STDEV & 0.8046402 & 0.245054 & 0.2442133 & 0.346107 & 0.9492505 & 0.283862 \\
\hline RSD & 0.8096463 & 0.244245 & 0.2448657 & 0.345256 & 0.9502914 & 0.283343 \\
\hline
\end{tabular}

\subsubsection{Robustness}

The robustness was studied by evaluating the effect of small but deliberate variations in the chromatographic conditions. An assay was performed with the following variations:optimum conditions, $5^{\circ}$ Chigher or lower, $5 \%$ more or less organic solvent in the mobile phase, $5 \%$ increase or decrease in the flow rate of the mobile phase, and detection $3 \mathrm{~nm}$ above or below the detection wavelength. The results were collected and subjected to statistical treatments. The means, standard deviations and relative standard deviations for the assay under all studied conditions are shown in Table6.

Table. 6- Robustness of the methodof the method for CHD and pCA

\begin{tabular}{||c|c|c|c|}
\hline No & Condition & CHD & pCA \\
\hline $\mathbf{1}$ & Optimized conditions & 99.96036703 & 100.4801419 \\
\hline $\mathbf{2}$ & less 5 degree Celsius & 99.91153242 & 99.97778052 \\
\hline $\mathbf{3}$ & More 5 degree Celsius & 99.98848653 & 99.65306379 \\
\hline $\mathbf{4}$ & 5\% less flow rate & 100.2310422 & 100.065966 \\
\hline $\mathbf{5}$ & 5\% more flow rate & 99.9106038 & 99.96361541 \\
\hline $\mathbf{6}$ & 5\% less Organic solvent & 99.66974347 & 99.68066608 \\
\hline $\mathbf{7}$ & 5\% more Organic solvent & 100.1049996 & 99.9772377 \\
\hline $\mathbf{8}$ & 3nm less & 99.98613261 & 100.0817496 \\
\hline $\mathbf{9}$ & 3nm more & 99.78474648 & 99.98299257 \\
\hline \multicolumn{2}{|r|}{ Avg } & 99.94973935 & 99.98480151 \\
\hline & STDEV & 0.163854928 & 0.240950102 \\
\hline & RSD \% & 0.163937324 & 0.240986728 \\
\hline
\end{tabular}

\section{CONCLUSIONS}

In this study, a specific and reliable HPLC-UV procedure was developedto assessCHD and pCA in their mouth rinse pharmaceutical formulations. The most important feature in the proposed method is its simplicity, as this method can be used with the minimum requirements of an isocratic HPLC system (one pump), UV detection at the same wavelength (the most common detector and no gradient program required). The method was optimized to be used at ambient temperature (no column oven required). Moreover, the method is economically (flow rate $1.0 \mathrm{ml} / \mathrm{min}$ for $6 \mathrm{~min}$ per injection), the buffer solution is easy to prepare (Acetatebuffer solution without $\mathrm{pH}$ adjustment), and the method passed all tests of robustness. To the best of our knowledge, no simpler method has been reported for an assay ofthis drug and its degradation product. 
Themethod is applicable evenwith conventional HPLC systems,and there for, it can be used forquality control purposes.

\section{REFERENCES}

[1] PaulsonD. S;1993; efficacy evaluation of a 4\% chlorhexidine gluconate as a full-body shower wash; American Journal of Infection Control, 21(4), 205-209.

[2] AlbandarJ. M, Rise J, GjermoP andJohansen J. R; 1986; radiographic quantification of alveolar bone level changes; A 2-Year Longitudinal Study in Man; Journal of Clinical Periodontology; 13(3), 195-200.

[3] J. Albandar, Gjermo P, and Preus H;1994; Chlorhexidine use after twodecadesofover-the-counter availability;Journal of Periodontol; 465, 109-112.

[4] Fardal O and Turnbull R.S; 1986; a review of the literature on use of chlorhexidine in dentistry, J Am Dent Assoc;112, 8639.

[5] 5- Leonardo M.R., TanomaruFilho M., Silva L.A.B., Nelson Filho P., Bonifacio K.C; 1999; in vivo antimicrobial activity of $2 \%$ chlorhexidine used as a root canal irrigating solution; Journal of End Oden;25,167-171.

[6] Gjermo P; 1974; chlorhexidineindentalpractice; Journal of Clinical.Periodontal;1, 143-152.

[7] Block S. S; 1991; disinfection, sterilization and preservation; Lea and Febiger, Philadelphia; 274.

[8] Gupta C, Czubatyj A.M., Briski L.E.; 2007; comparison of two alcohol-based surgical scrub solutions with an iodine-based scrub brush for presurgical antiseptic effectiveness in a community hospital; Journal of Hospital Infection; 65, 65-71

[9] Drug Introduction- Chlorhexidine http://en.wikipedia.org/wiki/Chlorhexidine

[10] Denton G. W; 2001;chlorhexidine; 5th Edition; Lippincott Williams \& Williams; Philadelphia; 32.

[11] European Medicines Agency; 2006; guideline on the limits of genotoxic impurities; EMEA, CHMP, QWP; 251344; 1-8.

[12] Hebert V. R, MiddletonJ. R, TomaszewskaE and L. Fox K; 2003; methodology for quantifying residues of chlorhexidine in raw dairy milk; Journal of Agricultural and Food Chemistry; 51(3), 567-570.

[13] Tsuchiya H, Miyazaki Tand Ohmoto S; 1999; high-performance liquid chromatographic analysis of chlorhexidine in saliva after mouth rinsing," Caries Research; 33(2); 156-163.

[14] Pesonen T, HolmalahtiJand Pohjola J; 1995; determination of chlorhexidine in saliva using high performance liquid chromatography; Journal of Chromatography;665(1), 222-225.

[15] Cheung A.P,Mavar R, Carlson C and Chiang W.K; 1991; problems affectingtheliquidchromatographicquantitationofchlorhexidine digluconate in ophthalmic solutions; J. Pharm. Biomed. Anal; 9, 41-45.

[16] Zhu Y,YangYandQ.Q; 2003; determinationofchlorhexidineacetate in disinfectant by high performance liquid chromatography; J. Hygiene Res; 32(87), 51-52.

[17] Zhang D, Liang H, Zeng J and Rao G; 1995; a study on the simultaneous HPLC determination of chlorhexidine and its impurity4-chloroanilineinchinese; J.WestChinaUniver.Med. Sci; 26, 447-451.

[18] Lam Y.W, Chan D.C, Rodriguez S.Y, Lintakoon J.H and Lam T.H; 1993; sensitive high performance liquid chromatographic assay for the determination of chlorhexidine in saliva;Journal of Chromatography; 612, 166-171.

[19] Middleton J.R, Hebert V.R, Fox L.K, Tomaszewska E and Lakritz J; 2003; eliminationkineticsofchlorhexidineinmilkfollowing intramammary infusion to stop lactation in mastitis mammary glandquartersofcows, J.Am.Vet.Med.Assoc; 222,1746-1749.

[20] HaandY,Cheung A.P; 1995; newstability-indicatinghighperformance liquid chromatography assay and proposed hydrolytic pathways ofchlorhexidine; J.Pharm.Biomed.Anal;14,1327-1334.

[21] GavlickW.K; 1992; high performanceliquidchromatographicanalysis ofchlorhexidineandpchloroanilineusingaspecialtycolumnand a photodiode-array detector;Journal of Chromatography. A; 623, 375-380.

[22] L. Havlíková, L. Matysová, L. Nováková, R. Hájková, and P. Solich; 2007; HPLC determination of chlorhexidine gluconate and pchloroaniline in topical ointment; J. Pharm. Biomed. Anal; 43, 1169-1173.

[23] Below H, Assadian O, Baguhl R, Hildebrandt U, Jäger B, Meissnerd K,Leaper D.J and Kramer A;2017; measurements of chlorhexidine, p-chloroaniline, andp-chloronitrobenzene in saliva after mouth wash 
before andafter operation with $0.2 \%$ chlorhexidine digluconate in maxillofacial surgery: a randomized controlled trial ;British Journal of Oral and Maxillofacial Surgery; 55,150-155.

[24] Antônio Rubens Gonçalves, Heliara Lopes do Nascimento, Gustavo H. B. Duarte,Rosineide C. Simas, Adriana de Jesus Soares, Marcos NogueiraEberlin andLygiaAzevedo Marques; 2016; liquid chromatography-tandem mass spectrometry determination of $\mathrm{p}$-chloroaniline in gel and aqueous chlorhexidine products used in dentistry;Chromatographia; 79, 841-849

[25] Alain Nicolay, Estelle Wolff, Marie-France Vergnes, Jacques Kaloustian and Henri Portugal; 2011, rapid HPLC method for determination of para chloroaniline in chlorhexidine antiseptic agent in mouth rinses, ophthalmic and skin solution; American Journal of Analytical Chemistry; 2, 422-428.

[26] Marco A. Cardoso , Maria L. D. Fávero , João C. Gasparetto , Bianca S. Hess andDile P. Stremel Roberto Pontarolo; 2011; development and validation of an RP-HPLC method for the determination of chlorhexidine and p-chloroaniline in various pharmaceutical formulations; Journal of Liquid Chromatography \& Related Technologies; 34(15), 1556-1567

[27] Luiz Eduardo Barbin, Paulo César Saquy, DéboraFernandes Costa Guedes, ManoelDamião Sousa-Neto, Carlos Estrela, and Jesus DjalmaPécora; 2008; JOE; 34(12),1508 -1514.

[28] Matsushima H, Sugimoto K, Shibata Kand Sakurai N; 1982; determination by Mass fragmentography of the chlorhexidine in biological samples; Japanese Journal of Hygiene; 37(5), 762-767.

[29] Alder V. G, Burman D, Simpson R. A, Fysh Jand Gillespie W. A; 1980; Comparison of hexcchlorophane and Chlorhexidine powders in prevention of neonatal infection; Archives of Disease in Childhood; 55(4), 277-280.

[30] Read E; 1978; a note of hibitane assay with final iodination; Methodological Surveys in Biochemistry; Chichester Ellis, Horwwod,.

[31] GavlickW. K and DavisP. K, gas chromatographic determination of p-chloroaniline in a chlorhexidine digluconate-containing alcohol foam surgical scrub product," Journal of AOAC International, Vol. 77, No. 3, 1994, pp. 583-586.

[32] Ono A; 1982; gas-liquid chromatographic separation of toluidine, chloroaniline and dichloroaniline isomers on various stationary phases including heteroaromatic compounds; Analyst; 107(1275), 600-605.

[33] Luiz Eduardo Barbin, Carlos Estrela, ,Debora Fernandes Costa Guedes, ulioJC_esarEmboavaSpan_O., ManoelDamiao Sousa-Neto, and Jesus DjalmaPecora; 2013; detection of para-chloroaniline, reactive oxygen species, and 1-chloro-4-nitrobenzene in high concentrations of chlorhexidine and in a mixture of chlorhexidine and calcium hydroxide; JOE; 39(5), 664-668.

[34] Bettina R. Basrani, Sheela Manek, Dan Mathers, Edward Filleryand Rana N.S. Sodhi; 2010; determination of 4-chloroaniline and its derivatives formed in the interaction of sodium hypochlorite and chlorhexidine by using gas chromatography; JOE; 36(2), 312-314.

[35] de Vries J, Ruben $\mathbf{J}$ and Arends J; 1991; determination of chlorhexidine in saliva and in aqueous solutions; Caries Research; 25(6), 410-414.

[36] Jensen J. Eand Christensen F; 1971; a study of the elimination of chlorhexidine from the oral cavity using a new spectrophotometric method; Journal of Periodontal Research; 6(4), 306-311.

[37] Kamil P. Kolosowski, Rana N.S. Sodhi, Anil Kishen, and Bettina R. Basrani; 2014; qualitative analysis of precipitate formation on the surface and in the tubules of dentin irrigated with sodium hypochlorite and a final rinse of Chlorhexidine; JOE; 40(12), 2036-2040. 